\title{
Predictors of diffuse-type in-stent restenosis following drug-eluting stent implantation
}

\author{
CHANG-BUM PARK ${ }^{1}$ and HOON-KI PARK ${ }^{2}$ \\ ${ }^{1}$ Department of Internal Medicine, Graduate School of Medicine, Kyung Hee University at Gangdong, \\ Kyung Hee University; ${ }^{2}$ Department of Internal Medicine, Seoul Veterans Hospital, Seoul, Republic of Korea
}

Received December 10, 2012; Accepted February 13, 2013

DOI: $10.3892 /$ etm.2013.1024

\begin{abstract}
Diffuse-type in-stent restenosis (ISR) is known to be associated with a higher rate of restenosis than focal-type ISR. Therefore, it is clinically important to identify the determinants of diffuse-type ISR following drug-eluting stent (DES) implantation. We investigated the clinical, procedural and angiographic variables for predicting diffuse-type ISR following DES implantation. A total of 173 ISR lesions in 159 patients (diffuse-type: 61 lesions, focal-type: 112 lesions) following DES implantation from February 2003 to May 2008 were included in this study. Clinical, procedural and quantitative coronary angiographic variables were analyzed to determine predictors of diffuse-type ISR following DES implantation. Univariate analysis showed that the absence of hypertension [odds ratio (OR), 0.493; 95\% confidence interval (CI), 1.025-4.103, $\mathrm{P}=0.042]$, use of a paclitaxel-eluting stent (PES) (OR, 3.318; 95\% CI, 1.730-6.365, P<0.001) and smaller post-stenting minimal luminal diameter (MLD; OR, 0.368, 95\% CI, 0.168-0.808, $\mathrm{P}=0.013$ ) were significantly associated with diffuse-type ISR. However, use of a PES (OR, 3.957; 95\% CI, 1.977-7.922, $\mathrm{P}<0.001)$ and smaller post-stenting MLD (OR, 0.320; CI, 0.140-0.731, $\mathrm{P}=0.007$ ) were only independent predictors of diffuse-type ISR by multivariate analysis. Diabetes was not a predictor of diffuse-type ISR. The use of a PES and the post-stenting MLD were related to diffuse-type ISR following DES implantation.
\end{abstract}

\section{Introduction}

Routine stent implantation has been shown to have a better procedural success rate and clinical outcome than balloon angioplasty $(1,2)$. However, restenosis and repeat revascu-

Correspondence to: Dr Chang-Bum Park, Department of Internal Medicine, Division of Cardiology, Kyung Hee University Hospital at Gangdong, Kyung Hee University, 149, Sangil-dong, Gangdong-gu, Seoul 134-727, Republic of Korea

E-mail:wwwpcb@hanmail.net

Key words: stent, restenosis, predictor larization remain significant clinical problems limiting the long-term success of stent implantation (1-3).

Recent development of the drug-eluting stent (DES) has reduced the incidence of stent-related restenosis to $<10 \%$, but has not eliminated it completely $(4,5)$. Furthermore, diffuse-type in-stent restenosis (ISR; $\geq 10 \mathrm{~mm}$ in length) has also been shown to be associated with a higher rate of recurrent restenosis and poor prognosis than focal-type ISR in the DES (6), as well as in the bare metal stent (BMS) (7-9). However, little data is available concerning predictors of diffuse-type ISR following DES implantation.

Therefore, the present study sought to identify the predictors of diffuse-type ISR following successful DES implantation.

\section{Patients and methods}

Patients. Between February 2003 and May 2008, 2,485 consecutive patients underwent coronary DES implantation in 3,466 lesions at Seoul Veterans Hospital (Seoul, Korea). Angiographic follow-up was obtained for 2,403 eligible lesions in 1,722 patients (follow-up rate, $69.3 \%$ ), and the overall angiographic restenotic rate was $7.9 \%$ [189 lesions: sirolimus-eluting stent (SES), 107 lesions (56.6\%); paclitaxel-eluting stent, (PES), 82 lesions (43.4\%)]. Of these patients, 159 patients with 173 ISR lesions were enrolled in this study. Patients were excluded from this study if the treatment site was in the left main coronary artery $(n=12)$ or venous bypass graft $(n=4)$. This study was conducted in accordance with the Declaration of Helsinki and with approval from the institutional review board from the Kyung Hee University Hospital at Gangdong (Seoul, Korea).

Stenting procedure. An SES (Cypher ${ }^{\mathrm{TM}}$; Cordis Corporation, Miami, FL, USA) or PES (Taxus ${ }^{\mathrm{TM}}$; Boston Scientific, Natric, MA, USA) was used in all patients. Stent implantation was performed according to standard techniques, and stents were selected at the physician's discretion. Complete lesion coverage was recommended as well as angiographic optimization with $<20 \%$ residual stenosis by visual estimation. During the procedure, patients received a bolus of $100 \mathrm{IU} / \mathrm{kg}$ heparin, with a repeated bolus of 2,000 IU heparin to maintain the activated clotting time of $\geq 300 \mathrm{sec}$. All patients were treated with aspirin 100-200 mg/day indefinitely and clopidogrel $75 \mathrm{mg} /$ day for $\geq 6$ months. 
Table I. Clinical characteristics of 159 study patients.

\begin{tabular}{|c|c|c|c|}
\hline Characteristics & Diffuse-type ISR (n=51) & Focal-type ISR $(n=108)$ & P-value \\
\hline Age, years & $58.0 \pm 12.4$ & $59.0 \pm 9.9$ & 0.602 \\
\hline Male gender & $37(72.5 \%)$ & $76(70.4 \%)$ & 0.777 \\
\hline Diabetes & $10(19.6 \%)$ & $31(28.7 \%)$ & 0.221 \\
\hline Hypertension & $19(37.3 \%)$ & $59(54.6 \%)$ & 0.041 \\
\hline Current smoking & $19(37.3 \%)$ & $32(29.6 \%)$ & 0.336 \\
\hline Hypercholesterolemia ( $\geq 200 \mathrm{mg} / \mathrm{dl}$ ) & $12(23.5 \%)$ & $28(25.9 \%)$ & 0.745 \\
\hline Prior PCI & $11(21.6 \%)$ & $24(22.0 \%)$ & 0.926 \\
\hline Prior CABG & $0(0 \%)$ & $1(0.9 \%)$ & 1.000 \\
\hline Clinical presentation & & & 0.757 \\
\hline Stable angina & $27(52.9 \%)$ & $65(60.2 \%)$ & \\
\hline Unstable angina & $13(25.5 \%)$ & $21(19.4 \%)$ & \\
\hline NSTEMI & $4(7.8 \%)$ & $10(9.3 \%)$ & \\
\hline STEMI & $7(13.7 \%)$ & $12(11.2 \%)$ & \\
\hline $\operatorname{LVEF}(\%)$ & $59.2 \pm 8.8$ & $58.3 \pm 8.5$ & 0.540 \\
\hline Multivessel disease & $28(54.9 \%)$ & $51(47.2 \%)$ & 0.336 \\
\hline
\end{tabular}

Data are presented as mean \pm SD or n (\%).PCI, percutaneous coronary intervention; CABG, coronary artery bypass surgery; STEMI, ST-segment elevation myocardial infarction; NSTEMI, non-ST-segment elevation myocardial infarction; LVEF, left ventricular ejection fraction.

Angiographic analysis. Coronary angiograms were analyzed by two experienced investigators who were not aware of the purpose of the study. The reference vessel diameter, the percent diameter stenosis and the minimal luminal diameter were determined using an online quantitative coronary angiographic system (Xelera Cath 1.1, Philips, The Netherlands) at baseline, subsequent to the procedure and again at follow-up. The angiographic measurement was made during the end-diastole following intracoronary nitroglycerin administration.

Definitions. Demographic, clinical, angiographic and procedural characteristics were prospectively entered into the angiographic database of Seoul Veterans Hospital. Angiographic restenosis was defined as a diameter stenosis of $\geq 50 \%$ occurring in the segment inside the stent or a $5-\mathrm{mm}$ segment proximal or distal to the stent at follow-up angiography. Patterns of restenosis were defined as follows; focal type: restenosis with a $\geq 50 \%$ luminal narrowing and $<10 \mathrm{~mm}$ in length; and diffuse type: restenosis with a $\geq 50 \%$ lumimal narrowing and $\geq 10 \mathrm{~mm}$ in length.

Statistical analysis. Data were expressed as the mean \pm SD for continuous variables and frequencies for categorical variables. Continuous variables were compared by unpaired Student's t-test and categorical variables by Chi-square test. Univariate regression analysis was performed on variables with a P-value of less than 0.05 to identify determinants of restenosis and variables found to be significant by univariate analysis were entered into multivariate analysis to determine their independent relationship to restenosis. A P-value of $<0.05$ was considered to indicate a statistically significant result.

\section{Results}

Focal-type ISR developed in 112 lesions and diffuse-type ISR in 61 lesions. Follow-up angiography after coronary stenting was conducted a mean of $6.63 \pm 1.70$ months after the procedure. Clinical, angiographic, and procedural variables were analyzed in this study and are summarized in Tables I and II. The diffuse-type ISR group had a lower incidence of absence of hypertension than the focal-type ISR group (37.3 vs. $54.6 \%$, respectively, $\mathrm{P}=0.041)$, and a higher incidence of use of a PES (63.9 vs. 34.8\%, respectively, $\mathrm{P}<0.001$ ) and post-stenting minimal luminal diameter (MLD; $2.50 \pm 0.39$ vs. $2.67 \pm 0.44 \mathrm{~mm}$, respectively, $\mathrm{P}=0.011)$. However, diabetes was not significantly more common in diffuse-type ISR (19.6 vs. $28.7 \%$, respectively, $\mathrm{P}=0.221$ ).

Univariate analysis revealed that the absence of hypertension [odds ratio (OR), 0.493; 95\% confidence interval (CI), 1.025-4.103, $\mathrm{P}=0.042]$, use of a PES (OR, 3.318; 95\% CI, 1.730-6.365, $\mathrm{P}<0.001)$, and smaller post-stenting MLD (OR, $0.368 ; 95 \% \mathrm{CI}, 0.168-0.808, \mathrm{P}=0.013)$ were significantly associated with diffuse-type ISR. However, use of a PES (OR, 3.957; 95\% CI, 1.977-7.922, $\mathrm{P}<0.001)$ and smaller post-stenting MLD (OR, 0.320; CI, 0.140-0.731, P=0.007) were only independent predictors of diffuse-type ISR by multivariate analysis (Table III).

\section{Discussion}

This study showed that post-stenting MLD and the use of a PES are independent predictors of diffuse-type ISR. These results suggest that the largest possible post-stenting MLD and prudent selection of the type of DES are required to reduce the incidence of diffuse-type ISR. 
Table II. Procedural and angiographic variables for 173 study lesions.

\begin{tabular}{|c|c|c|c|}
\hline Variables & Diffuse-type ISR (n=61) & Focal-type ISR (n=112) & P-value \\
\hline \multicolumn{4}{|l|}{ Lesion characteristics } \\
\hline Target coronary vessel & & & 0.973 \\
\hline Left anterior descending & $35(57.4 \%)$ & $66(58.9 \%)$ & \\
\hline Left circumflex & $7(11.5 \%)$ & $13(11.6 \%)$ & \\
\hline Right coronary & $19(31.1 \%)$ & $33(29.5 \%)$ & \\
\hline Type B2/C lesions & $51(83.6 \%)$ & $102(91.0 \%)$ & 0.772 \\
\hline Chronic total occlusion & $7(11.5 \%)$ & $12(10.7 \%)$ & 0.878 \\
\hline Restenotic lesion & $6(9.8 \%)$ & $13(11.6 \%)$ & 0.722 \\
\hline Ostial lesion & $2(3.3 \%)$ & $10(8.9 \%)$ & 0.162 \\
\hline Bifurcation & $7(11.5 \%)$ & $18(16.1 \%)$ & 0.411 \\
\hline \multicolumn{4}{|l|}{ Procedural characteristics } \\
\hline Balloon/artery ratio & $1.26 \pm 0.18$ & $1.28 \pm 0.19$ & 0.568 \\
\hline Stent per lesion & $1.66 \pm 0.87$ & $1.73 \pm 0.74$ & 0.572 \\
\hline Stent length per lesion, mm & $42.2 \pm 25.1$ & $45.0 \pm 23.7$ & 0.453 \\
\hline Use of PES & $39(63.9 \%)$ & $39(34.8 \%)$ & $<0.001$ \\
\hline \multicolumn{4}{|l|}{ Quantitative coronary angiography } \\
\hline Lesion length, mm & $35.9 \pm 19.7$ & $38.4 \pm 20.8$ & 0.429 \\
\hline Reference vessel diameter, $\mathrm{mm}$ & $2.71 \pm 0.53$ & $2.77 \pm 0.43$ & 0.448 \\
\hline \multicolumn{4}{|l|}{ Pre-intervention } \\
\hline Minimal luminal diameter, mm & $0.71 \pm 0.49$ & $0.80 \pm 0.55$ & 0.286 \\
\hline Diameter stenosis, $\%$ & $72.3 \pm 17.4$ & $70.5 \pm 19.6$ & 0.544 \\
\hline \multicolumn{4}{|l|}{ Post-intervention } \\
\hline Minimal luminal diameter, $\mathrm{mm}$ & $2.50 \pm 0.39$ & $2.67 \pm 0.44$ & 0.011 \\
\hline Diameter stenosis, $\%$ & $4.63 \pm 16.0$ & $2.8 \pm 14.8$ & 0.350 \\
\hline Postprocedural TIMI 3 flow & $58(95.1 \%)$ & $111(99.1 \%)$ & 0.126 \\
\hline Acute gain & $1.76 \pm 0.50$ & $1.88 \pm 0.60$ & 0.202 \\
\hline IVUS guidance & $36(59.0 \%)$ & $81(72.3 \%)$ & 0.074 \\
\hline
\end{tabular}

Data are presented as mean \pm SD or $\mathrm{n}(\%)$. PES, paclitaxel-eluting stent; TIMI 3, thrombolysis in myocardial infarction grade 3; IVUS, intravascular ultrasound.

Table III. Predictors of angiographic restenosis by logistic regression analysis.

\begin{tabular}{lccccrrr}
\hline & \multicolumn{3}{c}{ Univariate analysis } & & \multicolumn{2}{c}{ Multivariate analysis } \\
\cline { 2 - 4 } \cline { 5 - 6 } Variables & OR & $95 \%$ CI & P-value & & OR & $95 \%$ CI & P-value \\
\hline Use of PES & 3.318 & $1.730-6.365$ & $<0.001$ & & 3.957 & $1.977-7.922$ & $<0.001$ \\
Post-stenting MLD & 0.368 & $0.168-0.808$ & 0.013 & & 0.320 & $0.140-0.731$ & 0.007 \\
Hypertension & 0.493 & $0.249-0.975$ & 0.042 & & 0.507 & $0.253-1.014$ & 0.055 \\
\hline
\end{tabular}

OR, odds ratio; CI, confidence interval; PES, paclitaxel-eluting stent; MLD, minimal luminal diameter.

Coronary stenting has become a standard therapy for coronary artery disease due to the simplicity of the procedure and its favorable outcomes. Recent randomized trials showed that the implantation of a DES dramatically reduced restenosis $(4,5)$. However, restenosis continues to affect a significant number of patients with more complex lesions; therefore, more effective strategies are required.

Intravascular ultrasound has shown that ISR is the result of neointimal hyperplasia rather than elastic recoil $(10,11)$. Mehran et al (9) developed an angiographic classification of 
ISR according to the geographic distribution of the intimal hyperplasia, demonstrating that repeat revascularization increases with increasing ISR class: pattern I (focal ISR, 19\%), pattern II (diffuse ISR within the stent, 35\%), pattern III (diffuse ISR outside the stent, 50\%) and pattern IV (totally occluded ISR, 83\%). Diffuse-type ISR reflects exaggerated neointimal hyperplasia as compared with the focal-type ISR and carries a higher rate of re-restenosis following BMS implantation and balloon angioplasty. Recently developed DESs have been shown to be effective in reducing binary restenosis in de novo lesions in randomized controlled trials by $0-9 \%(4,5)$. While this number is a great improvement over the results seen with BMS implantation, it is certainly not negligible. Furthermore, diffuse-type ISR following DES implantation is rare but continues to be associated with a higher rate of re-restenosis (6), as does BMS implantation $(12,13)$. For these reasons, the identification of the predictors of diffuse-type ISR in DES implantation may play an important role in determining treatment strategies and prognosis.

In DES as well as BMS implantation, post-stenting MLD is one of the most powerful coronary morphologic predictors of restenosis among the many determinants of coronary morphology. Our data demonstrated that a smaller post-stenting MLD is associated with diffuse-type ISR. However, little is known concerning the relationship between diffuse-type ISR and post-stenting MLD. We suggest that a greater stent area may contribute to a decreased rate of diffuse-type ISR in patients with DES implantation but more investigative studies are required to confirm this hypothesis.

The current study also demonstrated that the use of a PES is associated with diffuse-type ISR. Other studies have reported similar results; the incidence of diffuse-type ISR following PES implantation has been reported to be $38-50 \%(14,15)$, compared with $0-14 \%$ following SES implantation $(16,17)$. Furthermore, large clinical trials have also demonstrated that the SES is superior to the PES with regard to angiographic restenotic rate and late luminal loss $(18,19)$. Whether this finding represents a more exaggerated neointimal response to the PES remains to be seen in the ongoing and the upcoming randomized trials between the two types of DES currently available on the market.

With DES, as with as BMS, diabetes continues to be an independent risk predictor of restenosis. Furthermore, a previous study (20) showed that diabetes was associated with diffuse-type ISR following BMS implantation. However, our results revealed that diabetes was not a predictor of restenosis following DES implantation, suggesting that the characteristics of ISR may be significantly different in the DES than in the BMS in diabetic patients but additional data are required to confirm this.

There were several potential limitations to the present study. Firstly, the choice of DES was made by the physician, which may have lead to a possible selection bias. Secondly, this study was a retrospective, single center study. Finally, our study was limited by the incomplete use of intravascular ultrasound. Despite these limitations, this study is based on one of the largest angiographic databases, and has identified independent predictors of diffuse-type ISR in DES implantation.

\section{References}

1. Stone GW, Grines CL, Cox DA, Garcia E, Tcheng JE, Griffin JJ, Guagliumi G, Stuckey T, Turco M, Carroll JD, Rutherford BD and Lansky AJ; Controlled Abciximab and Device Investigation to Lower Late Angioplasty Complications (CADILLAC) Investigators: Comparison of angioplasty with stenting, with or without abciximab, in acute myocardial infarction. N Eng J Med 346: 957-966, 2002.

2. Grines CL, Cox DA, Stone GW, Garcia E, Mattos LA, Giambartolomei A, Brodie BR, Madonna O, Eijgelshoven M, Lansky AJ, O'Neill WW and Morice MC; Stent Primary Angioplasty in Myocardial Infarction Study Group. Coronary angioplasty with or without stent implantation for acute myocardial infarction. N Eng J Med 341: 1949-1956, 1999.

3. Odell A, Gudnason T, Andersson T, Jidbratt H and Grip L: One-year outcome after percutaneous coronary intervention for stable and unstable angina pectoris with or without application of general usage of stents in unselected European patient groups. Am J Cardiol 90: 112-118, 2002.

4. Moses JW, Leon MB, Popma JJ, Fitzgerald PJ, Holmes DR, O'Shaughnessy C, Caputo RP, Kereiakes DJ, Williams DO, Teirstein PS, Jaeger JL and Kuntz RE; SIRIUS Investigators: Sirolimus-eluting stents versus standard stents in patients with stenosis in a native coronary artery. N Eng J Med 349: 1315-1323, 2003.

5. Stone GW, Ellis SG, Cox DA, Hermiller J, O'Shaughnessy C, Mann JT, Turco M, Caputo R, Bergin P, Greenberg J, Popma JJ and Russell ME; TAXUS-IV Investigators: A polymer-based, paclitaxel-eluting stent in patients with coronary artery disease. N Eng J Med 350: 221-231, 2004.

6. Saia F, Lemos PA, Arampatizis CA, Hoye A, Degertekin M, Tanabe K, Sianos G, Smits PC, van der Giessen WJ, de Feyter PJ, van Domburg RT and Serruy PW: Routine sirolimus eluting stent implantation for unselected in-stent restenosis: insights from the rapamycin eluting stent evaluated at Rotterdam Cardiology Hospital (RESEARCH) registry. Heart 90: 1183-1188, 2004.

7. Ragosta M, Samady H, Gimple LW, Sarembock IJ, Fenster M and Powers ER: Percutaneous treatment of focal vs. diffuse in-stent restnosis: A prospective randomized comparison of conventional therapies. Catheter Cardiovasc Interv 61: 344-349, 2004.

8. Ong AT, Aoki J, McFadden EP and Serruys PW: Classification and current treatment options of in-stent restenosis. Present status and future perspectives. Herz 29: 187-194, 2004.

9. Mehran R, Dangas G, Abizaid AS, Mintz GS, Lansky AJ, Satler LF, Pichard AD, Kent KM, Stone GW and Leon MB: Angiographic patterns of in-stent restenosis: Classification and implications for long-term outcome. Circulation 100: 1872-1878, 1999.

10. Hoffmann R, Mintz GS, Mehran R, Pichard AD, Kent KM, Satler LF, Popma JJ, Wu H and Leon MB: Intravascular ultrasound predictors of angiographic restenosis in lesions treated with Palmaz-Schatz stents. J Am Coll Cardiol 31: 43-49, 1998.

11. Dussaillant GR, Mintz GS, Pichard AD, Kent KM, Satler LF, Popma JJ, Wong SC and Leon MB: Small stent size and intimal hyperplasia contribute to restenosis: a volumetric intravascular ultrasound analysis. J Am Coll Cardiol 26: 720-724, 1995.

12. Bauters C, Banos JL, Van Belle E, McFadden EP, Lablanche JM and Bertrand ME: Six-month angiographic outcome after successful repeat percutaneous intervention for in-stent restenosis.Circulation 97: 318-321, 1998.

13. Yokoi H, Kimura T, Nakagawa Y, Nosaka H and Nobuyoshi M: Long-term clinical and quantitative angiographic follow-up after the Palmaz-Schatz stent restenosis. J Am Coll Cardiol 27: 224A, 1996.

14. Iakovou I, Schmidt T, Ge L, Sangiorgi GM, Stankovic G, Airoldi F, Chieffo A, Montorfano M, Carlino M, Michev I, Corvaja N, Cosgrave J, Gerckens U, Grube E and Colombo A: Angiographic patterns of restenosis after paclitaxel-eluting stent implantation. J Am Coll Cardiol 45: 805-806, 2005.

15. Stones GW, Ellis SG, Cannon L, Mann T, Greenberg JD, Spriggs D, O'Shaughnessy CD, DeMaio S, Hall P, Popma JJ, Koglin J and Russell ME; TAXUS V Investigators: Comparison of a polymer-based paclitaxel-eluting stent with a bare metal stent in patients with complex coronary artery disease: a randomized controlled trial. JAMA 294: 1215-1223, 2005. 
16. Lemos PA, Saia F, Ligthart JM, Arampatzis CA, Sianos G, Tanabe K, Hoye A, Degertekin M, Daemen J, McFadden E, Hofma S, Smits PC, de Feyter P, van der Giessen WJ, van Domburg RT and Serruys PW: Coronary restenosis after sirolimus-eluting stent implantation: morphological description and mechanistic analysis from a consecutive series of cases. Circulation 108: 257-260, 2003.

17. Colombo A, Orlic D, Stankovic G, Corvaja N, Spanos V, Montorfano M, Liistro F, Carlino M, Airoldi F, Chieffo A and Mario CD: Preliminary observations regarding angiographic pattern of restenosis after rapamycin-eluting stent implantation. Circulation 107: 2178-2180, 2003.

18. Windecker S, Remondino A, Eberli FR, Jüni P, Räber L, Wenaweser P, Togni M, Billinger M, Tüller D, Seiler C, Roffi M, Corti R, Sütsch G, Maier W, Lüscher T, Hess OM, Egger M and Meier B: Sirolimus-eluting and paclitaxel-eluting stents for coronary revascularization. N Eng J Med 353: 653-662, 2005.
19. Dibra A, Kastrati, A, Mehilli J, Pache J, Schühlen H, von Beckerath N, Ulm K, Wessely R, Dirschinger J and Schömig A; ISAR-DIABETES Study Investigators: Paclitaxeleluting or sirolimus-eluting stents to prevent restenosis in diabetic patients. N Eng J Med 353: 663-670, 2005.

20. Lee SG, Lee CW, Hong MK, Park HK, Kim JJ, Park SW and Park SJ: Predictors of diffuse-type in-stent restenosis after coronary stent implantation. Catheter Cardiovasc Interv 47: 406-409, discussion 410, 1999. 